\title{
Examination of the Relationship between the Preschool Teachers' Attitudes towards Mathematics and the Mathematical Development in 6-Year-Old Preschool Children
}

\author{
Meryem ÇELIK ${ }^{1}$ \\ ${ }^{1}$ Department of Educational Pre-School, Education Faculty, Düzce University, Düzce, Turkey \\ Correspondence: Meryem ÇELIK, Department of Educational Pre-School, Education Faculty, Düzce University, \\ Düzce, Turkey. E-mail: mtancelik@gmail.com
}

Received: April 6, 2017

Accepted: May 5, 2017

Online Published: May 18, 2017

doi:10.5539/jel.v6n4p49

URL: http://doi.org/10.5539/jel.v6n4p49

\begin{abstract}
This study was carried out to determine whether there is a relationship between the preschool teachers' attitudes towards mathematics and mathematical development in 6-year-old preschool children. The sampling of the study was consisted of 30 teachers working with 6 years old children and their 120 students in public kindergartens and independent preschool classrooms in Erzurum City. Teachers' attitudes towards mathematics education were measured using the "Preschool Teachers' Attitudes towards Early Mathematics Education Determination Tool" and the levels of mathematical development in children were measured using the "Progress in Math 6 Test". Collected data were analyzed using both descriptive and predictive statistical methods. Results presented that there was a positive and significant relationship between the preschool teachers' attitudes towards mathematics and the mathematics development in 6-year-old preschool children. Furthermore, the preschool teachers' attitudes towards mathematics were also determined to have an effect on the selection of mathematics skill areas included in the programs. According to these results, it can be said that teachers' attitudes towards mathematics directly affect the mathematical development in children.
\end{abstract}

Keywords: early childhood education, teacher attitude, mathematical development

\section{Introduction}

The conception of attitude is used for the things that we like and enjoy. It may represent the summary product of a more active process of propositional reasoning that involves careful scrutiny of the validity of information regarding the attitude object (Fazio, 1995). Personal beliefs are an important factor in development of attitude. Even though concepts of attitude and belief are related, they are different words. While attitude refers to the personal enjoyment, belief is the knowledge (Sweeting, 2011). Teachers learn whether they like mathematics or not from their experiences. Their attitudes lead their mathematic activities and affect their experiences. Teachers' beliefs regarding to mathematics have a great impact on shaping their behaviors. There is a mutual relationship between teachers' common attitude towards mathematics and beliefs (Thiel, 2010). Beliefs about mathematics was directly affected by the attitude (Ajen, 1989). If a student believe that mathematics are hard, she usually will have a negative attitude as well.

Bodis, Cusworth (1997) and Sax (1994) think that previous mathematical experience has an effect on students' confidence on maths (Roberts, Crecthley, \& Harman, 1998). Shuck (1996) suggests that a student's previous negative mathematical experiences were then the strongest "chain" among the causes that slowed down his progress in mathematics.

Teachers are the most important factors in the success of children (Polly, 2008). Teachers affect learning and development of the students in many ways. They provide information directly, but also provide educational experiences that will indirectly direct students' expectations and enthusiasm. These indirect effects may be strong enough to influence academic achievement (Tran et al., 2012). Preschool teachers must meet the needs of their children as much as they need (Thornton, Crim, \& Hawkins, 2009). One of these requirements is the development of math skills.

Children learn mathematics at school with the experiences teachers provide them. That is why children's understanding mathematics, using mathematical skills when solving problems, trusting in themselves, and being 
interested in mathematics are shaped by what is given in the school. Teachers' knowledge and beliefs about mathematics influence children's mathematical development (Thornton et al., 2009; Kilday, Kinzie, Mashburn, $\&$ Whittaker, 2011). Teachers' thoughts about mathematics have an important influence on their interaction with children, their teaching, and their decision making when teaching curricula (Evans, 2003). Teachers' attitudes toward mathematics also affect their teaching of mathematics (Ma, 1997; Gellert, 1999; Lee, 2005; Brown, 2005; Brown et al., 2008; Sweeting, 2011). Moreover, it is thought that teachers' negative attitudes towards mathematics affects children's attitudes towards mathematics (Bush, 1989; Bursal \& Paznokas, 2006; Malinsky, Ross, Pannells, \& McJunkin, 2006; Peker \& Mirasyedioğlu, 2008; Gresham, 2008; Peker, 2009). There is research that suggests a relationship between the qualifications of teachers and their children's academic achievements (Roberts et al., 1998; Brown et al., 2008; Thornton, 2009). In his work Krap (1991) found that teachers who have positive attitudes towards mathematics use various methods for their progress in mathematics, which reflects positively on children's attitudes toward mathematics and that teachers with negative attitudes toward mathematics use teacher-centered methods, which causes a decrease in children's math success (cited in Lee, 2005; Lee, 2005). These attitudes that have begun to shape in early childhood can last up to adulthood (Sweeting, 2011).

This study was conducted to determine whether there is a relationship between the attitudes of preschool teachers to mathematics and mathematics development of 6-year-old children. In the general aim of the research, these questions were tried to be answered; "Is there a meaningful relationship between the average of the points obtained from the Preschool Teachers' Attitudes to Early Mathematics Education and the average of the scores obtained from the Children's Mathematics Development 6 Test in the general purpose of the research?", "Is there a meaningful relationship between the early mathematical skills taken place in the programs of the preschool teachers and children's math development average scores?" and "Is there a meaningful relationship Preschool teachers' attitudes towards early mathematics education and early mathematical skills areas in their programs?"

Early mathematical development is largely linked to the attitudes of preschool teachers towards mathematics. Teachers with positive attitudes are thought to have frequently applied activities for their math skills areas in their programs. It is considered that revealing preschool teachers' attitudes towards mathematics by examining the effect of them on children's mathematical development and educational programs will contribute to the improvement of the teachers' awareness and the educational studies to be done in this area.

\section{Methods}

The model of this research is the screening model. According to Karasar (1999): "Screening models are research approaches that aim to describe past or present conditions as they appear. The event, individual or object that is subject to research is tried to be defined as it is within its own conditions. No attempt is made to alter or influence them in any way. There is something to be known and it is there". The relationships that are found through the screening are interpreted rather than a cause-and-effect relationship. In a context in which if one of the variable's status is known, the other variable is predicted. There are two types of relational screening: Correlation and Comparison.

\subsection{Study Group}

The target population of the research is composed of the teachers working in elementary schools and independent kindergartens attached to the Ministry of Education in Erzurum in June 2013 and the children in the classes of these teachers.

In the creation of the sample, firstly, a list showing the kindergartens in primary schools and independent kindergartens affiliated to Erzurum Provincial Directorate of Education was obtained. Obtained lists were examined and interviewed by school administrators and kindergarten teachers by the researcher. The study group was determined by random sampling method. Thirty teachers working in these primary and independent kindergartens and four (totally 120) children selected randomly from each teacher's class were studied.

\subsection{Data Collection Tools}

In the research, the teachers' attitudes towards mathematics education were measured by "Tool for Determining Attitudes of Preschool Teachers to Early Mathematics Education" and the children's mathematical development levels were measured by "Progress in Math 6". The information on what kind of mathematical activities the teachers put in preparing their programs were gathered with the "Teacher Information Form". 


\subsection{Tool for Determining Attitudes of Preschool Teachers towards Early Mathematics Education}

Attitude determination tool was developed by Tokgöz (2006) and were re-factored by Alisinanoğlu, Güven and Kesicioğlu in 2009; it is a Likert-type scale consisting of 18 items including preschool teachers' attitudes towards early mathematics education of 4-6-year-old children. The items were scored as " 1 strongly agree, 2 agree, 3 undecided, 4 disagree, 5 strongly disagree". The minimum score to be taken from the scale is 18 , the maximum score to be taken is 90 . The scale has a three-factor structure. These are; Attitudes Towards the Mathematical Skills of the Preschool Child (Articles 3, 5, 6, 8, 9, 10, 11, 13, 14), Attitudes Towards the Environment of Early Mathematics Education (articles 7, 16, 17, 21, 22), Attitudes Towards the Early Mathematics Education (articles 15, 18, 19, 20).

\subsubsection{Progress in Maths 6 Test}

The original form of the Progress in Math 6 Test was developed by Clausen et al. (2004) in the United Kingdom, and its validity and reliability were tested. The adaptation to Turkish, validity and reliability studies were carried out by Çelik and Kand1 (2011). As a result of the reliability analysis, the Alpha correlation was found to be .80 and CR-20 $=0.81$. The test-retest correlation was determined to be .95 according to the analysis results.

In the Progress in Math 6 Test, questions are divided into categories as number, shape, area, and measures as included in the curriculum. The questions in this test are also divided into process categories as knowing the facts and methods, using concepts, solving daily problems, and conducting logic. This test is administered in groups to children who are six years old or who will reach this age within the current school year. The test has 24 questions and takes about 35 minutes. The highest score to be obtained from the test is 28 , the lowest score is 0 . In the Progress in Math 6 Test, the contents of the Test Book are not arranged according to the order of difficulty. The more difficult questions are interspersed among the easy ones to keep the children motivated.

\subsection{Data Collection}

In order to determine whether there is a relationship between the attitudes of preschool teachers to mathematics and the mathematics development of 6-year-old preschool children, "Tool for Determining Attitudes of Preschool Teachers to Early Mathematics Education" was implemented to the teachers in the study group and "Progress in Math 6 Test" was implemented to the four groups of randomly selected children in the same study group by the researcher in the direction of the application guidelines. The information on what kind of mathematical activities the teachers took when preparing their programs was obtained as a result of the researcher applying the "Teacher Information Form" to the teachers in the study group.

\subsection{Data Analysis}

Statistical analyzes were carried out by evaluating the data collected by "Progress in Math 6", "Tool for Determining Attitudes of Preschool Teachers to Early Mathematics Education", and "Teacher Information Form".

\section{Results}

The results of the research conducted to determine whether there is a relationship between the attitudes of preschool teachers to mathematics and the mathematics development of 6-year-old preschool children are presented below. The attitudes of preschool teachers according to the three sub-factors related to early mathematics education and the information on the average and standard deviations of children's mathematics development are given in Table 1.

Table 1. Attitude score average and standard deviations of preschool teachers according to three sub-factors related to early mathematics education

\begin{tabular}{llll}
\hline Sub factors & N & Avg & Ss \\
\hline A.T. M. S. P. C. & 30 & 34.13 & 4.65 \\
A. T. E. M. E. E. & 30 & 18.00 & 3.73 \\
A. T. E. M. E. & 30 & 17.06 & 2.36 \\
Total & 30 & 69.73 & 10.74 \\
\hline
\end{tabular}

Attitudes Towards Mathematical Skills of Preschool Children (A. T. M. S. P. C.).

Attitudes Towards Early Mathematics Education Environment (A. T. E. M. E.E.).

Attitudes Towards Early Mathematics Education (A. T. E. M. E.). 
When we look at Table 1, it is seen that the standard deviation of the first sub-factor of teachers' early mathematics education is higher than the standard deviation of the second and third sub-factors. Considering that the average score of the three sub-factors is 69.73 , it can be said that teachers' attitude scores on early mathematics education are high.

Table 2. Score averages and standard deviations of children's mathematical development

\begin{tabular}{llll}
\hline Variables & $\mathrm{N}$ & Avg & Ss \\
\hline Mathematical Development & 120 & 13.8 & 4.6 \\
\hline
\end{tabular}

As a result of the descriptive analyzes made in Table 2, the average score of children's mathematical development is 13.9. It is seen that the mathematical developments of children are at a low level when considering that the test applied has 24 items and the highest score that can be taken is 28 , the lowest score is 0 .

Table 3. Pearson correlation analysis results of preschool teachers' attitudes according to three sub factors of early mathematics education and the average of children's mathematical development scores

\begin{tabular}{|c|c|c|}
\hline \multicolumn{3}{|c|}{ Mathematical Development Scores } \\
\hline \multicolumn{3}{|l|}{ Pearson Correlation } \\
\hline & A. T. M. S. P.C. & $.59^{*}$ \\
\hline & A. T. E. M. E. E. & $.41 *$ \\
\hline & A. T. E. M. E. & $.42 *$ \\
\hline & $\mathrm{N}$ & 30 \\
\hline
\end{tabular}

$\mathrm{p}<.05$.

When Table 3 is examined, it is seen that there is a positive and significant relationship between the attitudes of the kindergarten teachers according to the three sub-factors towards mathematics and the mathematical development of the 6-year-old children. $\mathrm{R}=.59, \mathrm{r}=.41, \mathrm{r}=.42$. As the result of the statistics, when the attitude scores towards the mathematics of the teachers increase, it is seen that the scores of the mathematics development of the children are also increased.

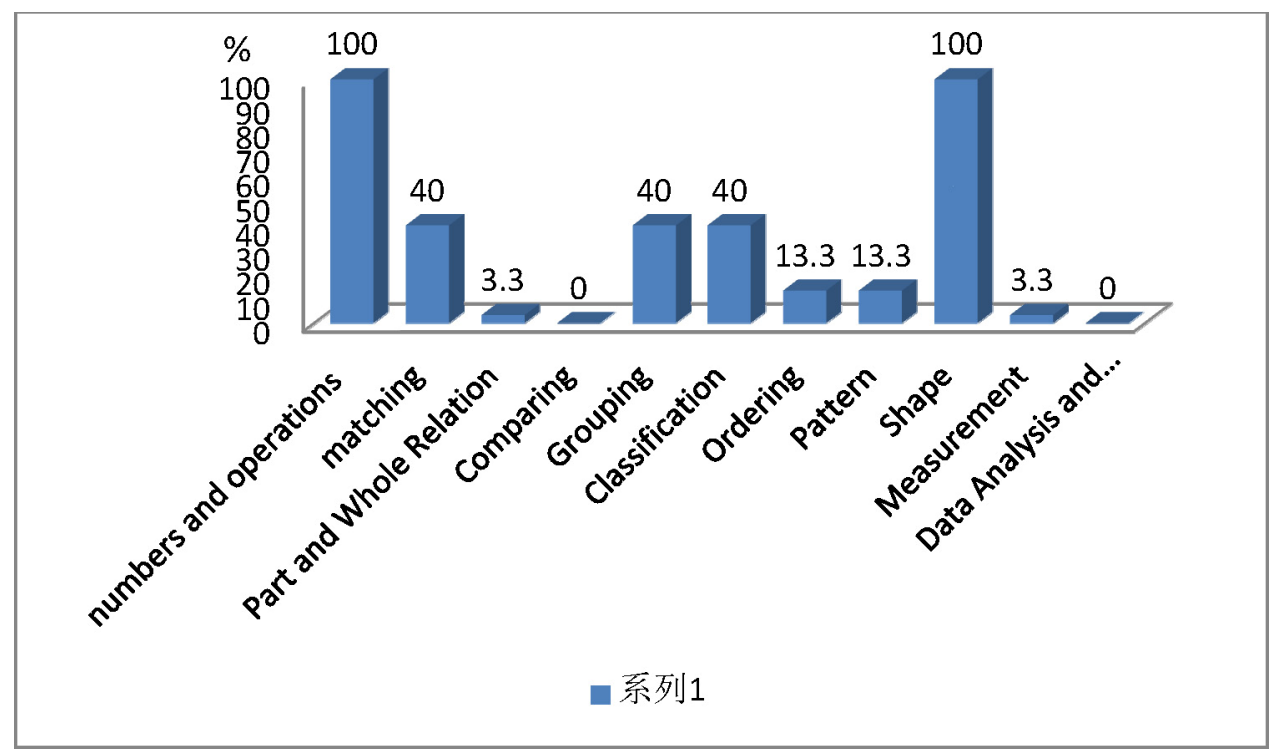

Figure 1. Results of early mathematical abilities in preschool teachers' programs 
In Figure 1, when the early mathematical skills in preschool teachers' programs are examined, the numbers and the ability of the operations are included in the programs by all of the teachers' while the matching, grouping and classification skills are included by $40 \% .13 .3 \%$ of the teachers give place the ordering and modeling skills, $3.3 \%$ of the teachers give place to whole-part relationship and measurement in their programs. All of the teachers do not include comparative graphics and data analysis skills in their programs.

Table 4. Pearson correlation analysis results of early mathematical abilities and mathematical development average scores of preschool teachers' programs

Mathematical Development Scores

Pearson Correlation
E. M. S.
$.74 *$
$\mathrm{N}$
30

$\mathrm{p}<.01$.

Early Mathematical Skills (E. M. S.).

When Table 4 is examined, it is seen that there is a positive and significant relationship between the early mathematics skills in preschool teachers' programs and the mathematics development of 6-year-old kindergarten children. $\mathrm{R}=\mathbf{7 4}$. As a result of the statistics, the mathematical development scores of the children seem to increase as the areas of early mathematics skills in the teachers' programs are increased.

Table 5. Pearson correlation analysis results of early mathematical skills in preschool teachers' attitudes and programs related to early mathematics education

E. M. S. P.T. A. P.

\begin{tabular}{lll}
\hline \multicolumn{1}{c}{ E. M. S. P.T. A. P. } \\
\hline Pearson Correlation & & $.59^{*}$ \\
& E.M. S. P.T. & 30 \\
\hline
\end{tabular}

$\mathrm{p}<.01$.

Preschool Teachers Attitudes towards Early Mathematics Education (P.T. A.T. E. M. E.).

Areas of Early Mathematics Skills (A. E. M. S.).

Table 5 shows that there is a positive and significant relationship between preschool teachers' attitudes towards early mathematics education and early mathematical skills areas in their programs. $\mathrm{R}=.59$. As a result of the statistics, it is observed that as the scores of teachers' attitudes towards early mathematics education increase, the areas of early mathematics skills that they have included in their programs increase.

\section{Conclusion and Discussion}

As a result of descriptive statistics, teachers' attitudes towards early mathematics education were found to be high. This result shows that preschool teachers have a positive attitude towards mathematics. Anders and Rossbach (2015) also found that teachers did not have more negative attitudes towards mathematics than other professions (Baroody, Lai, \& Mix, 2006). These results also coincide with the conclusion that in Thiel's (2010) study in Germany, most preschool teachers are open minded towards mathematics.

As the result of the statistics, the attitude scores of the teachers towards mathematics increase, it is seen that the scores of the mathematics development of the children are also increased. This finding is also supported by other research findings that examine the effect of teachers' attitudes towards mathematics on their children's mathematics development.

It is thought that there is a causal effect between the attitudes of teachers towards mathematics and the achievements of students in mathematics. In other words, teachers who have more positive attitudes towards mathematics have students with higher mathematical achievement. The results of the research show that teachers 
"attitudes toward mathematics play a significant role in the factors that affect students" achievement in mathematics (Ethington \& Wolfle, 1984, 1986; Lester, Garofalo, \& Kroll, 1989; Loeb, 1993; Marshall, 1989; cited in Ma, 2012; Ma, 2012).

Stipek et al. (2001) found that teachers' attitudes towards mathematics and learning affected their teaching practices. In this study, it is found that while the teachers with positive attitudes towards teaching mathematics and mathematics encourage students frequently in the teaching process, teachers who have math anxiety and negative attitudes spend significantly less time on mathematics. Children who do not have enough math applications for their mathematical development remain at a low level in this area (Thiel, 2010).

Lee (2005) examined the relationship between the attitudes of 81 preschool teachers towards mathematics and their mathematical practice. In the results of the research, it was determined that kindergarten teachers' attitudes towards mathematics teaching are highly related to mathematical applications suitable for children's development.

In 1991, Karp investigated how teachers' attitudes toward mathematics affected the methods they used in teaching mathematics. In the research, teachers with positive attitudes have used their teaching methods using various materials and different methods, and teachers with negative attitudes have used one-way teacher-centered methods.

Teachers with mathematics anxiety focus on the results without considering the solving process in students' answers. The failure of teachers to teach mathematics has also led to the failure of many learners (Thiel, 2010). Trice and Okben studied the 40 teachers in 1987 from second grade to fifth grade to examine the relationship between mathematical concerns and mathematics teaching practices. The results of the research show that teachers are very anxious about spending less time in mathematics and that they are avoiding mathematics teaching as their level of anxiety increases.

In 2007, Chouinard, Karsenti and Roy found that teacher belief influenced students' beliefs about mathematics learning. This study has shown that the support received from the teacher affects the students' beliefs about mathematics. Teachers influence students' beliefs on their abilities, their attitudes about mathematics, and their efforts and goals in learning mathematics. This study has shown that teachers' beliefs and expectations can shape students' perception of learning abilities by influencing their achievement. All these study results show that teachers' mathematical beliefs not only play a role on teaching methods of teachers but also affect their students' behaviors and achievements (Roberts, Cretchley, \& Harman, 1998).

\section{References}

Ajzen, I. (1989). Attitude Structure and Behavior. In A. R. Pratkanis, S. J. Beckler, \& A. G. Greenwald (Eds.), Attitude structure and function (pp. 241-274). Hillsdale, NJ: Lawrence Erlbaum.

Anders, Y., \& Rossbach, H. G. (2015). Preschool teachers' sensitivity to mathematics in children's play: The influence of math-related school experiences, emotional attitudes, and pedagogical beliefs. Journal of Research in Childhood Education, 29, 305-322. https://doi.org/10.1080/02568543.2015.1040564

Alisinanoğlu, F., Güven, G., \& Kesicioğlu, O. S. (2009). The analysis of preschool teacher candidates' attitudes about early mathematics education in the views of various variables. Procedia Social and Behavioral Sciences, 1, 2197-2201. https://doi.org/10.1016/j.sbspro.2009.01.386

Baroody, A., Lai, M., \& Mix, K. (2006). The development of young children's number and operation sense and its implications for early childhood education. In B. Spodek, \& O. Saracho (Eds.), Handbook of research on the education of young children (pp. 187-221). Mahwah, NJ: Lawrence Erlbaum.

Brown, E. T., Victoria J., Molfese, V. J., \& Molfese, P. (2008). Preschool Student Learning in Literacy and Mathematics: Impact of Teacher Experience, Qualifications, and Beliefs on an At-Risk Sample. Journal of Education for Students Placed at Risk (JESPAR), 13(1), 106-126. https://doi.org/10.1080/10824660701860474

Brown, E. T. (2005). The Influence of Teachers' Efficacy and Beliefs Regarding Mathematics Instruction in the Early Childhood Classroom. Journal of Early Childhood Teacher Education, 26(3), 239-257. https://doi.org/10.1080/10901020500369811

Bursal, M., \& Paznokas, L. (2006). Mathematics Anxiety and Pre-Service Elementary Teachers' Confidence to Teach Mathematics and Science. School Science and Mathematics, 106(4), 173-179. https://doi.org/10.1111/j.1949-8594.2006.tb18073.x 
Bush, W. S. (1989). Mathematics anxiety in upper elementary school teachers. School Science and Mathematics, 89(6), 499-509. https://doi.org/10.1111/j.1949-8594.1989.tb11952.x

Chouinard, R., Karsenti, T., \& Roy, N. (2007). Relations among Competence Beliefs, Utility Value, Achievement Goals, and Effort in Mathematics. British Journal of Educational Psychology, 77, 501-517. https://doi.org/10.1348/000709906X133589

Gellert, U. (1999). Prospective Elementary Teachers' Comprehension of Mathematics İnstruction. Educational Studies in Mathematics, 37(1), 23-43. https://doi.org/10.1023/A:1026492400537

Gresham, G. (2008). Mathematics Anxiety and Mathematics Teacher Efficacy in Elementary Pre-Service Teachers. Teaching Education, 19(3), 171-184. https://doi.org/10.1080/10476210802250133

Karasar, N. (2005). Scientific Research Method. Nobel Publishing, Ankara.

Kilday, C. R., Kinzie, M. B., Mashburn, A. J., \& Whittaker, J. V. (2011). Accuracy of Teacher Judgments of Preschoolers' Math Skills. Journal of Psychoeducational Assessment, 30(2), 148-159. https://doi.org/10.1177/0734282911412722

Lee, J. (2005). Correlations between kindergarten teachers' attitudes toward mathematics and teaching practice. Journal of Early Childhood Teacher Education, 25(2), 173-184. https://doi.org/10.1080/1090102050250210

Ma, X. (1997). Reciprocal Relationships between Attitude toward Mathematics and Achievement in

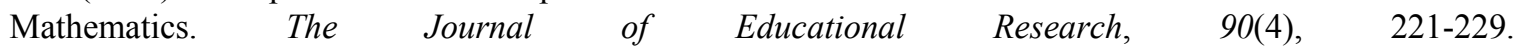
https://doi.org/10.1080/00220671.1997.10544576

Peker, M. (2009). Pre-Service Teachers' Teaching Anxiety about Mathematics and Their Learning Styles. Eurasia Journal of Mathematics, Science \& Technology Education, 5(4), 335-345.

Peker, M., \& Mirasyedioğlu, Ş. (2008). Pre-Service Elementary School Teachers' Learning Styles and Attitudes towards Mathematics. Eurasian Journal of Mathematics, Science \& Technology Education, 4(1), 21-26.

Polly, D. (2008). Modeling the Influence of Calculator Use and Teacher Effects on First Grade Students' Mathematics Achievement. The Journal of Combuters in Mathematics and Science Teaching, 27(3), 245-263.

Roberts, C., Cretchley, P., \& Harman, C. (1998). Measuring Attitudes towards Mathematics in Early Childhood and Primary Teacher Education. from http://www.merga.net.au/documents/RP_Roberts_Cretchley_Harman_1998.pdf

Sax, L. J. (1994). Mathematical self-concept: How college reinforces the gap. Research in Higher Education, 35(2), 141-166. https://doi.org/10.1007/BF02496699

Schuck, S. (1996). Chains in primary teacher mathematics education courses: An analysis of powerful constraints. Mathematics Education Research Journal, 8(2), 119-136. https://doi.org/10.1007/BF03217293

Stipek, D., Givvin, K. B., Salmon, J. M., \& MacGyvers, V. L. (2001). Teachers' beliefs and practices related to mathematics instruction. Teaching and Teacher Education, 17, 213-226. https://doi.org/10.1016/S0742-051X(00)00052-4

Sweeting, K. (2011). Early Years Teachers' Attitudes towards Mathematics (Master's Thesis). Queensland University of Technology.

Thiel, O. (2010). Teachers' attitudes towards mathematics in early childhood education. European Early Childhood Education Research Journal, 18(1), 105-115. https://doi.org/10.1080/13502930903520090

Thornton, J. S., Crim, C. L., \& Hawkins, J. (2009). The Impact of an Ongoing Professional Development Program on Prekindergarten Teachers' Mathematics Practices. Journal of Early Childhood Teacher Education, 30(2), 150-161. https://doi.org/10.1080/10901020902885745

Tran, N. A., Schneider, S., Duran, L., Conley, A. M., Richland, L., Burchinal, M., ... Martinez, M. E. (2012). The Effects of Mathematics İnstruction Using Spatial Temporal Cognition on Teacher Efficacy and Instructional Practices. Computers in Human Behavior, 28, 340-349. https://doi.org/10.1016/j.chb.2011.10.003 


\section{Copyrights}

Copyright for this article is retained by the author(s), with first publication rights granted to the journal.

This is an open-access article distributed under the terms and conditions of the Creative Commons Attribution license (http://creativecommons.org/licenses/by/4.0/). 